\title{
Medicamentosa keratoconjunctivitis: A case report
}

\begin{tabular}{|c|c|}
\hline \multicolumn{2}{|c|}{$\begin{array}{l}\text { Authors: } \\
\text { Chiemela C. Okoro }{ }^{1} \\
\text { Onyekachukwu M. } \\
\text { Amiebenomo }^{2} \\
\text { Nwakuso Aruotu }\end{array}$} \\
\hline \multicolumn{2}{|c|}{$\begin{array}{l}\text { Affiliations: } \\
{ }^{1} \text { RISE Clinic Nigeria, Adazi-Ani, } \\
\text { Anambra State, Nigeria }\end{array}$} \\
\hline \multicolumn{2}{|c|}{$\begin{array}{l}{ }^{2} \text { Department of Optometry, } \\
\text { University of Benin, Nigeria }\end{array}$} \\
\hline \multicolumn{2}{|c|}{$\begin{array}{l}{ }^{3} \text { University of Port Harcourt } \\
\text { Teaching Hospital, Nigeria }\end{array}$} \\
\hline \multicolumn{2}{|c|}{$\begin{array}{l}\text { Corresponding author: } \\
\text { Chiemela Okoro, } \\
\text { oakmela@gmail.com }\end{array}$} \\
\hline \multicolumn{2}{|c|}{$\begin{array}{l}\text { Dates: } \\
\text { Received: } 10 \text { May } 2014 \\
\text { Accepted: } 15 \text { Dec. } 2014 \\
\text { Published: } 24 \text { Mar. } 2016\end{array}$} \\
\hline \multicolumn{2}{|c|}{$\begin{array}{l}\text { How to cite this article: } \\
\text { Okoro CC, Amiebenomo OM, } \\
\text { Aruotu N. Medicamentosa } \\
\text { keratoconjunctivitis: A case } \\
\text { report. Afr Vision Eye Health. } \\
\text { 2016;75(1), a20. http:// } \\
\text { dx.doi.org/10.4102/aveh. } \\
\text { v75i1.20 }\end{array}$} \\
\hline \multicolumn{2}{|c|}{$\begin{array}{l}\text { Copyright: } \\
\text { (c) 2016. The Authors. } \\
\text { Licensee: AOSIS. This work is } \\
\text { licensed under the Creative } \\
\text { Commons Attribution } \\
\text { License. }\end{array}$} \\
\hline \multicolumn{2}{|l|}{ Read online: } \\
\hline 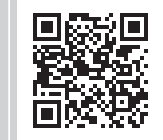 & $\begin{array}{l}\text { Scan this QR } \\
\text { code with your } \\
\text { smart phone or } \\
\text { mobile device } \\
\text { to read online. }\end{array}$ \\
\hline
\end{tabular}

We present a case of medicamentosa keratoconjunctivitis in a 42-year-old woman who complained of eye redness, blurred vision and pain after using inappropriate medications for treatment. Examination revealed severe conjunctival injection as well as punctate stains on the corneas. The patient was advised to stop her former medications and was prescribed an artificial tear supplement, an antibiotic-steroid combination and a topical nonsteroidal anti-inflammatory drug. Possible conditions that could elicit similar clinical features are highlighted. The purpose of the case report is to raise issues relating to drug-induced allergic/sensitivity reactions based on recent clinical and experimental reports and also the roles of active ingredients and preservatives.

\section{Introduction}

Medicamentosa keratoconjunctivitis (MK) is a descriptive term used to refer to ocular reactions to ocular solutions and medications that produce a more substantial keratitis. ${ }^{1} \mathrm{MK}$ is generally a punctate keratopathy; however, the condition has other clinical features that enable the clinician to distinguish MK from other causes of superficial punctate keratopathy., ${ }^{2,3}$ Often, there is a history of use of topical ocular medications that may interfere with epithelial cell membrane physiology. Compromise of the corneal epithelium occurs when such medications are used for prolonged periods. ${ }^{2}$ If the ocular surface is disturbed by other factors such as tear film disorders, keratoconjunctivitis can occur with less exposure to a drug than would otherwise be the case.

Self-medication is a common practice in Africa and especially amongst people of low socioeconomic status who seldom see medical personnel for proper management of their health problems. Not untypically, they eventually present to clinics with an array of topical ophthalmic medications that they have been using at home for ocular problems without much improvement. Some have bought these drugs from local pharmacies after diagnosing themselves with conjunctivitis - a condition locally known in Nigeria as 'Apollo' or described as 'worms' crawling around their eyes. In addition, some patients borrow topical medications from friends and family members whilst others obtain inappropriate prescriptions from unqualified persons including medical personnel who are not eye care practitioners. When these medications are applied to the eyes, they elicit unintended outcomes that force patients to seek professional help.

It has been shown that the risk of adverse drug reactions is related to the number of prescription items taken. ${ }^{4}$ Consequently, multiple drug use increases the probability of drug interactions, and toxicity of drug combination may be synergistic and greater than the risks associated with each drug alone. However, even eye care practitioners may be guilty of overtreating patients, with certain topical agents to clear the eyes of microbial pathogens, without knowing that the medications themselves sometimes can be deleterious to ocular tissues. ${ }^{5}$ For example, topical antibiotics, especially aminoglycosides such as tobramycin, gentamicin and antibiotic-steroid combinations that contain neomycin as well as contact lens solutions, are notorious for their potential corneal toxicity. ${ }^{5}$

The drugs mainly implicated are formulated with benzalkonium chloride (BAK), a preservative known to cause hypersensitivity reactions. ${ }^{5,6}$ Unfortunately, most topical antimicrobial agents contain BAK and, with frequent instillation, a significant epitheliopathy may result. ${ }^{7}$

\section{Case report}

A 42-year-old housewife presented with the chief complaints of eye redness, blurred vision and pain that started four days after applying chloramphenicol powder mixed with water to her eyes. She referred to her condition as 'Apollo' and said that the attendant discomfort after the drug use forced her to consult a general practitioner (GP) who prescribed gentamicin eyedrops, doxycycline capsules and paracetamol tablets which she used for one week; her condition 
subsequently worsened. Pain and photophobia ensued, particularly in the left eye, and the pain in the left eye soon started radiating down to the left side of her face and neck. Her medical history was non-contributory to her condition.

\section{Diagnostic data}

Visual acuity with a projected Snellen chart measured 20/50 OD and 20/60+2 OS. Pupils were reactive to light and there was no evidence of afferent pupillary defect. Ocular motility was also smooth, accurate, full and extensive. Anterior segment examination with a slit-lamp biomicroscope revealed a grade $2+$ conjunctival injection OD and grade 3 conjunctival injection OS. There was no follicular reaction at the fornix or any palpable preauricular lymphadenopathy. The left cornea appeared more oedematous than the right and also showed more punctate staining with fluorescein.

Intraocular pressure using a Goldmann applanation tonometer measured $8 \mathrm{mmHg}$ OU and undilated fundoscopy showed (0.25) cup-to-disc ratio with healthy (pink) neuroretinal rims.

\section{Differential diagnosis}

The differential diagnoses of superficial punctate keratopathy include the following considerations:

- Contact lens solutions and care products are generally under-recognised but can cause intolerance to contact lens wear. ${ }^{8}$ Conjunctival injection, epithelial staining, punctate epithelial keratopathy, erosions and microcysts are all potential signs of conjunctival or corneal toxicity from contact lens solutions.

- Preservative and cleaning agents such as thimerosal, BAK, chlorhexidine, hydrogen peroxide and other compounds used for chemical sterilisation can cause an immediate, severe epitheliopathy with accompanying pain. Thimerosal can cause a delayed hypersensitivity response, resulting in conjunctivitis, keratitis with epithelial involvement, and coarse epithelial and subepithelial opacities. It has also been implicated in contact lens-induced superior limbic keratoconjunctivitis whose ocular signs include injection of the superior bulbar conjunctiva, epitheliopathy of the cornea and conjunctiva, papillary conjunctivitis and some superficial pannus. ${ }^{8}$

- Dry eye syndrome, which emerges with symptoms of burning or foreign body sensations with tearing, often exacerbated by smoke, wind, heat and low humidity, or prolonged use of the eye could present with punctate corneal and/or conjunctival staining with fluorescein or rose bengal. The staining occurs inferiorly or in the interpalpebral area. ${ }^{9}$ Excess mucus or debris in the tear film and filaments may be found on the cornea.

- Aminoglycosides are a class of drug represented by gentamicin, tobramycin and neomycin. ${ }^{10}$ The first two are the only members of this class with broad-spectrum antibiotic properties, which allows them to function as stand-alone drugs. They exert their bactericidal action by inhibition of bacterial protein synthesis. ${ }^{10}$ While all aminoglycosides have the potential to cause ocular surface toxicity, and systemic reactions, this is not a practical concern when used for a short time, as they would be rationally prescribed in eye care, unless the ocular surface was already compromised prior to instillation of the treatment. ${ }^{10}$

- Indiscriminate use of topical anaesthetics can cause serious ocular toxicities and complications. ${ }^{11}$ Local anaesthetics are known to decrease corneal damage threshold, ${ }^{11}$ and inhibit epithelial migration and division. ${ }^{12}$ Loss of microvilli, reduction of desmosomes and other intracellular contacts, and swelling of mitochondria and lysosomes have been reported.12 In these disorders, punctate keratopathy is initially seen and then, as the abuse continues, the eye becomes more injected and epithelial defects appear to transform into a neurotrophic-like appearance. ${ }^{12}$

- Factitious (artificial as against natural) disorders include a spectrum of self-induced injuries with symptoms or physical findings intentionally produced by the patient in order to assume a sick role. Factitious conjunctivitis usually shows evidence of mechanical injury to the inferior and nasal quadrants of the cornea and conjunctiva. The areas of involvement show sharply delineated borders linear or square. Patients often have medical training or work in a medical setting, and they generally show an attitude of serene indifference. ${ }^{12}$

- Other conditions involved with superficial punctate lesions are herpetic corneal disease, delayed postsurgical epithelial healing, Thygeson superficial punctate keratopathy, ${ }^{3}$ chemical burns, recurrent corneal erosions, anterior segment necrosis, infections or neuro-paralytic keratopathy. ${ }^{12}$

Finally, based on this specific patient's drug history and clinical features, she was diagnosed with medicamentosa keratoconjunctivitis. To control the serious pain in the left eye, a drop of homatropine was instilled in-office to relax the ciliary muscles and to forestall any anterior chamber reaction. She was also given a transiently preserved artificial tear supplement (Optive) to be applied profusely during the day. A new nonsteroidal anti-inflammatory drug (Bromday, one drop daily) as well as a Tobadex, four times daily, were also given, and a specific instruction to return to clinic after two days. She was subsequently advised to stop taking her previous medications.

\section{First follow-up}

The patient returned two days later for follow-up; her visual acuity had improved to $20 / 30 \mathrm{OD}$ and $20 / 40^{+1}$ OS. There was still recognisable corneal epithelial staining, more on the left eye than the right, but improvement was evident and the pain in the left eye was gone. Intraocular pressure was $6 \mathrm{mmHg}$ OD and $10 \mathrm{mmHg}$ OS. However, the patient was informed to continue her medications and report back to clinic five days later. 


\section{Second follow-up}

Seven days after first follow-up, the patient came back with further improvement in her vision. Visual acuity improved to $20 / 20^{-2}$ OD and $20 / 25$ OS. Her intraocular pressure was $9 \mathrm{mmHg}$ OU. She presented with minimal corneal epithelial stains and was therefore told to continue her medication and come back after two weeks. However, the patient did not come back and was subsequently lost to further follow-up.

\section{Discussion}

The preceding case typifies ocular medicamentosa caused by the use of many ocular medications for long periods, leading to toxicity of the cornea. Chemical irritation of ocular tissues by a topically applied drug/preservative or cosmetic, or delayed hypersensitivity (cell-mediated) response to a topical drug/preservative or cosmetic, highlights the aetiology. ${ }^{13}$ Whatever the mechanism, there may be a delay in onset of weeks or months following a symptom-free period.

Several agents are capable of producing signs and symptoms of ocular medicamentosa. ${ }^{14}$ The agents may be prescribed or self-inflicted. The effect may be caused by a drug, its solvent or vehicle, or the preservative used. Some ophthalmic drugs/preservatives likely to cause problems are brimodine, prostaglandin analogues (particularly bimatoprost, atropine, neomycin and acyclovir), preservatives such as BAK, and lanolin (constituent of ointment bases). ${ }^{13}$

Generally, patients present in one of two ways: either with unexplained red eye, oblivious of a causative vector; or stating that the eye was accidentally exposed to something noxious. ${ }^{15}$ There may be an initial improvement in the condition requiring treatment before deterioration ensues, despite proper compliance with the regimen. Symptoms such as irritation, ocular pain, stinging, burning, photophobia, ocular redness, lid swelling and blurred vision may be apparent. ${ }^{13}$

Keratitis associated with this condition causes chemosis that is not firm, warm or painful to the touch. According to Sowka et al. ${ }^{15}$, the term 'watchglass' is employed in some instances because the dome appearance of the conjunctiva, as it is juxtaposed against the cornea, resembles a watchglass's interface with its casing. Likewise, the eye and adnexa may be involved, with a response ranging from itching to fullblown urticaria.

Furthermore, specific signs associated with ocular medicamentosa include diffuse punctate staining of the cornea, and/or conjunctiva more prominent with Bengal (lissamine green) than fluorescein. Chronic epithelial defects owing to toxic inhibition of epithelial healing occur as well as corneal oedema, pseudodendrites and disciform stromal infiltrates. $^{13}$

Topical anaesthetic abuse initially results in non-specific clinical features of toxicity but, when fully developed, has the characteristic findings of coalescent corneal infiltrate, iritis, a Wessely ring and hypopyon. ${ }^{12}$ Thiomersal keratoconjunctivitis produces a superior corneal punctate keratopathy, neovascularisation, corneal opacity and, in a few cases, corneal epithelial failure.

Worthy of mention is the hypersensitivity reaction arising from contact lens solutions, though the advent of new multipurpose solutions has reduced the incidence. Exposure to chemical agents in contact lens care systems gives a hyperaemic reaction that is usually bilateral. ${ }^{16}$ According to Morris, ${ }^{16}$ proteolytic enzymes and preservatives in contact lens solutions are all toxic but reactions are unusual unless the irritant is in a particularly high concentration or is held in contact with the eye for a prolonged period. ${ }^{16}$

Factitious disease occurs either as a result of topical preparations or from mechanical trauma. Topical anaesthetics and more toxic antivirals (iduxuridine and trifluorothymidine) are amongst the more commonly abused drops. $^{12}$ Mucous fishing syndrome and congenital and acquired corneal anaesthesia, particularly in children, can be mistaken for factitious disease. ${ }^{11}$

Toxic or allergic response is considered to be an overreaction of the body's immune system to immunogens or allergens, and can be innate or acquired. The overreaction manifests when the body responds hyperactively to an exogenous material. ${ }^{15}$ The chemical may be overtly destructive and the resultant tissue response is generated by the release of cytokines or chemo-attractants.

The immune system has two divisions, each containing several components. The cellular immune system has a cellular component (leukocytes and other supportive cells) and a humoral component (antibodies), the system that relies primarily on the cellular system to recognise foreign substances and initiate attack. ${ }^{15}$ The components of the cellular system include granulocytes (neutrophils, basophils, eosinophils) and macrophages (phagocytise antigen and present it to T-cells). The cellular immune system also includes T-helper lymphocytes that recognise foreign proteins presented by macrophages and bind to them, causing the release of lymphokines and alerting other lymphocytes to the presence of foreign antigens and cytotoxic T-cells that destroy abnormal host cells. ${ }^{15}$ Suppressor T-cells also play a role by suppressing the immune response. B-cells differentiate into plasma cells, producing antibodies against foreign invaders. An antibody is a complex glycoprotein produced by plasma cells that are highly specific for the antigens that stimulated their production. Mast cells and their inflammatory cascade are included as members of the immune system. ${ }^{15}$

There are four types of hypersensitivity reactions:

1. Type I reactions are immediate hypersensitivity or anaphylactic reactions. They produce sudden mass degranulation of mast cells mediated by the antibody IgE. ${ }^{15}$

2. Type II reactions are classified as autoimmune and involve a body reactions. They produce sudden mass 
degranulation of mast cells mediated by the anent of the system give rise to diseases in which auto-antibodies are produced and directed against the host. ${ }^{15}$

3. Type III reactions involve the combined formations of antigen and antibody known as immune complexes. According to Sowka et al., ${ }^{15}$ offending triggers may be intrinsic (e.g. a protein molecule) or extrinsic (e.g. a penicillin molecule), producing a significant tissue response. ${ }^{15}$

4. Type IV reactions, referred to as cell-mediated hypersensitivity reactions, involve T-lymphocytes and lymphokines. The reaction is usually delayed until a sufficient volume of antigens stimulate the cascade. Here the individual has the potential to respond when appropriate level antigens become present. Cosmetics are common allergens and usually result in delayed hypersensitivity (Type IV immune reaction) which is similar to that for poison ivy or poison oak. The Type I and IV reactions govern toxic/allergic kerato-conjunctival disease including that in discourse. ${ }^{15}$

Ocular tissues respond to these chemical exchanges by appearing as conjunctival and adnexal vaso-dilation, ${ }^{15}$ producing chemosis and oedema. Conjunctival follicles are hyperplasia of the lymphoid tissue within the eyelid stroma, and papillae comprise hyperplastic palpebral conjunctival epithelium infiltrated by lymphocytes and plasma cells.

BAK disrupts the cell walls by emulsifying membrane lipids, and hence both its effectiveness as a preservative and its toxicity to mammalian cells as lipids are a component common to all cell walls. ${ }^{11}$ It is typically used in concentrations of $0.001 \%-0.004 \% .{ }^{11}$ As reported by Baudouin and Traverso, ${ }^{17}$ the risk of ocular surface disease is increased greatly by BAK in topical glaucoma medications. Preservative-free treatments such as PF-tafluprost have proved beneficial.

In recent research cited by Sowka et al., ${ }^{15}$ there was a discovery of a long-term inflammatory up-regulation secondary to BAK. Also, Noecker and colleagues ${ }^{18}$ performed a randomised, controlled study of white rabbits in New Zealand which were instilled with BAK-containing anti-glaucoma medications such as Alphagan P, Xalatan, Trusopt, Lumigan, Refresh tears and Timolol. The corneas were evaluated with scanning electron microscopy and conjunctivas were evaluated with light microscopy. Corneal epithelial damage and conjunctival inflammation were graded by blinded observers according to standard scales. Results showed that the lowest scores were achieved by Alphagan P and Refresh tears, which was based on how these compounds affected the corneal epithelium. Following in order of lowest to highest scores were Lumigan, Timoptic, Xalatan and Trusopt. Trusopt caused the greatest amount of damage to the corneal epithelium. The amount of conjunctival inflammatory cell infiltration correlated with the amount of BAK in each medication.

In addition, patients with pre-existing dry eye syndrome can experience toxicity fairly quickly (Figure 1). ${ }^{19}$ If they have a normal tear film, it may take anywhere from a few months to a year to observe toxicity from BAK. Each person reacts

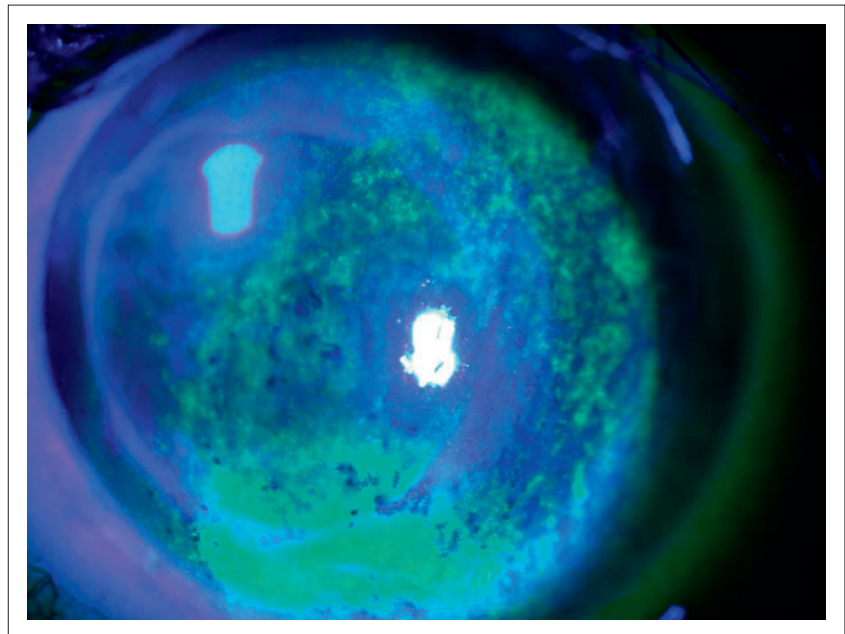

Source: Pflugfelder SC. Recognizing ocular surface disease in your office. Ophthalmo Management [serial on the Internet]. 2011 [cited 15 July 2012]. Available from: http://www. ophthalmologymanagement.com (image used with permission)

FIGURE 1: Extensive superficial punctate staining; this could be caused by benzalkonium chloride-exacerbated dry eye syndrome.

differently, and hence the need to examine their ocular status during the initial visit. Whilst only a small percentage of patients experience toxicity from BAK, the reaction can be quite severe for those who do. When a patient presents to a clinic with BAK-containing eye drops and toxicity is suspected, it is incumbent on the clinician to be aware of the signs (rapid tear film break-up time, corneal and conjunctival dye staining and lid margin and conjunctival redness) and pay attention to the symptoms that the patient complains about. ${ }^{19}$

Normally, management of medicamentosa or any other toxic/chemical keratoconjunctivitis is primarily aimed at eliminating the causative agent and reducing symptomatology. Cold compresses, artificial tears and ointments can soothe and lubricate the conjunctiva, skin and the cornea as needed. ${ }^{15}$ Topical antihistamine and oral anti-histamines are therapies for acute signs and symptoms. ${ }^{1}$ Nonsteroidal anti-inflammatory drugs may offer relief in moderate ocular cases. Our patient's condition was severe and therefore required corticosteroid therapy to quell the rampaging inflammatory reaction as well as an antibiotic cover for her affected cornea. Also, cycloplegia is given to relax the spasm of the ciliary muscles and, where necessary, bandage contact lenses are provided. Oral analgesics such as aspirin or ibuprofen can be used to settle the excessive discomfort and referred pain. Corneal oedema would involve the addition of topical hypertonic drops and ointments on a daily or four times daily basis to restore normal levels of hydration.

As clinicians, we are to note that prevention requires a high level of awareness of the potential for toxic keratoconjunctivitis. ${ }^{11}$ Avoiding the use of preserved medications or those known to be toxic (such as aminoglycosides, some glaucoma medications, and antivirals) in high-risk cases (chronic disease, dry eyes and patient on multiple topical therapies) will reduce the frequency of the problem. ${ }^{19}$ Furthermore, treatment without accurate diagnosis, or the identification 
of therapeutic aims, may lead to toxicity because treatment success is less likely to have been established, leading to prolonged therapy. ${ }^{20}$ Drug and preservative side-effects should be understood for each drug that is prescribed so that toxicity and allergy are included in the risk/benefit assessment for topical therapy.

\section{Conclusion}

Use of certain medications, and exposure of the eyes to chemical agents, can result in damage to the cornea or the conjunctiva or both, producing undesirable sensitivity reactions as in the case of medicamentosa. Thorough history and diligence on the part of the optometrist is paramount in identifying and managing such patients. Uncomplicated cases resolve within eight days even if left untreated. In toxic keratoconjunctivitis, there will be no palpable preauricular lymph nodes.

Clinicians must exercise caution in prescribing topical medications that may cause unexpected reactions owing to certain preservatives in them, especially aminoglycosides, antiviral agents and some glaucoma medications. Preservatives should always be considered in the differential diagnosis when managing poorly controlled external eye diseases, with the knowledge that patients on several preserved preparations are at greater risk of developing medicamentosa keratoconjunctivitis.

\section{Acknowledgement}

The authors thank the African Vision Research Institute for financial assistance with publishing page fees.

\section{Competing interests}

The authors declare that they have no financial or personal relationships which may have inappropriately influenced them in writing this article.

\section{Authors' contributions}

C.C.O. (RISE Clinic Nigeria) was the leader and primary contributor to the article. O.M.A. (University of Benin) further contributed to the work and ensured proper referencing. N.A. (University of Port Harcourt Teaching Hospital) provided educational guidance and mentoring.

\section{References}

1. Gurwood AS. Eye splotched after car wash botched. Rev Optom [serial on the Internet]. 2003 [cited 08 March 2012]. Available from: http://www.revoptom. com/diagnosticquiz

2. Coster DJ. Superficial keratopathy. Duane's Clinical Ophthalmolgy [serial on the Internet]. 2006. [cited 08 December 2014]. Available from: http://www.eyecalcs. com/almacen/medicina/oftamologia/enciclopedias/duane/pages

3. Thygeson P. Superficial punctate keratitis. J Am Med Assoc. 1950;144(18): 1544-1549. http://dx.doi.org/10.1001/jama.1950.02920180008004

4. Lawrenson J. Adverse drug reactions in elderly people. Optometry Today. 2009;49(21):30-36.

5. Kabat AG. Toxic/medicamentosa. Optometric Physician. E-newsletter. Rev Optom [newspaper online]. 2003 [cited 12 March 2008]. Available from: http://www. revoptom.com/optometricphysician

6. Burstein NL. Preservative cytotoxic threshold for benzalkonium chloride and chlorhexidine digluconide in cat and rabbit corneas. Invest Ophthalmol Vis Sci. 1980;19:308-313.

7. Baudouin C, Labbé A, Liang H, Pauly A, Brignole-Baudouin F. Preservatives in eyedrops: The good, the bad and the ugly. Prog Retin Eye Res. 2010;29(4) 312-334. http://dx.doi.org/10.1016/j.preteyeres.2010.03.001

8. Bowling E, Russell EG, Shovlin JP, Sindt CW. The corneal atlas. Rev Optom. 2010; $1-20$.

9. Cullum RD, Chang B, Freidberg MA, Rapuano CJ. The Wills eye manual: Office and emergency room diagnosis and treatment of eye disease. Philadelphia, PA: Lippincott Williams \& Wilkins, 1993; pp. 53-55, 63.

10. Melton R, Thomas R. Clinical guide to ophthalmic drugs. Rev Optom. 15 June 2010; S1-S52.

11. Epstein DL, Paton D. Keratitis from misuse of corneal anesthetics. N Engl J Med. 1968;279:396-399. http://dx.doi.org/10.1056/NEJM196808222790802

12. Wilhelmus KR, Huang AJW, Hwang DG, Parrish CM, Sutphin JE. Basic and clinical science course: External disease and cornea. Am Acad Ophthalmol. 1998-1999: 100-104.

13. Clinical management guidelines. Conjunctivitis medicamentosa (also dermatoconjunctivitis medicamentosa). London: The College of Optometrists; pp. 1-2.

14. Lagnado R, Alwitry A, Dua HS. Follicular conjunctivitis. Duane's Clinical Ophthalmology [serial on the Internet]. [cited 08 December 2014]. Available from: http://www.eyecalcs.com/almacen/medicina/oftamologia/enciclopedias/duane/ pages

15. Sowka JW, Gurwood AS, Kabat AG. Toxic/chemical keratitis. Handbook of ocular disease management. Rev Optom. 2009;20-22.

16. Morris J. Differentiating sight-threatening from non- sight threatening disease in contact lens wearers. Optometry Today. May 2006;41-46.

17. Baudouin C, Traverso CE. The role of preservative-free therapies in the treatment of glaucoma. Eur Ophthalmic Rev. 2013;7(2):74-80.

18. Noercker RJ. Effect of preservatives in chronic therapy. Ocular drug and surgical therapy update. Ocular Surg News. 2002:1-16.

19. Pflugfelder SC. Recognizing ocular surface disease in your office. Ophthalmol Management [serial on the Internet]. 2011 [cited 15 July 2012]. Available from: http://www.ophthalmologymanagement.com

20. Gupta D. Dry eye therapies: preventing patient self-prescribing. Optometric Management [serial on the Internet]. 2007 [cited 15 July 2012]. Available from: http://www.optometricmanagement.com 